\title{
Choosing the optimal frequency of water quality monitoring on tributaries of a lowland reservoir
}

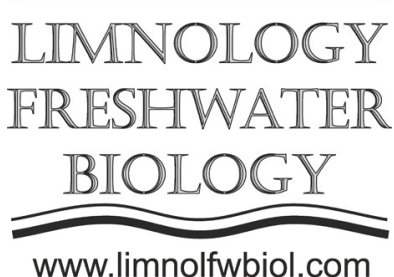

\author{
Sokolov D.I.*, Erina O., Tereshina M.A., Yakimova A.I. \\ Lomonosov Moscow State University, Leninskiye Gory, GSP-1, Moscow, 119991, Russia
}

\begin{abstract}
Water quality monitoring networks typically involve field measurements with time resolution ranging from daily or several times a week to just several times a year. This time step directly affects the reliability of any related calculations. We addressed the issue of setting the optimal monitoring frequency for different practical and research purposes. It is shown that monthly or even seasonal observations can be sufficient to estimate the annual chemical yield of a river, but to better describe the seasonal dynamics of the chemical flow it is necessary to increase the sampling frequency to at least twice per month. To explore the relationship between the water discharge and chemistry and to improve the model calculations dependent on chemical input it is necessary to establish the most detailed observation framework covering all key points of a yearly hydrograph. Regardless of specific objectives, it is recommended to always set flexible monitoring dates in accordance with the river's flow regime.
\end{abstract}

Keywords: water quality, monitoring frequency, lowland reservoir, tributaries

\section{Introduction}

When establishing a water quality monitoring framework, it is important to maintain strict regularity of field observations. The optimal sampling frequency is ideally determined by the natural variability of the target indicators, but in practice, the concerns of labor force, analytical and financial resources are given much more weight.

Consistent water quality data is crucial for efficient reservoir management (especially for drinking water reservoirs), as well as for research and forecasting purposes. Despite that, the official informational support for the Moscow City water supply system is rather irregular: on the tributaries of the Ivan'kovo Reservoir and the Moscow Canal, measurements are made twice a month, and on the rivers feeding the Mozhaysk Reservoir only 4-5 samples a year are taken.

It is evident that scarce measurements cannot ensure full understanding of the seasonal dynamics of most chemical components and their relationship with stream hydrology even with multi-annual data available. In this context, a question arises as to how large can the error of various estimates get depending on the data frequency.

\section{Material and methods}

To explore this question, we have performed multiple assessments of mineral and organic matter inflow into the Mozhaysk Reservoir via its two major tributaries - rivers Moskva and Lusyanka (Puklakov et al., 2015) - while artificially altering the input data at various degrees. We used data from extensive studies performed on the reservoir in 1984, 2012 and 2016, and simulated the reservoir's hydrodynamics with a quasi-two-dimensional model (Puklakov, 1999).

The three detailed field studies included determination of specific conductivity and chemical oxygen demand, which serve as indirect measures of total mineral and organic matter content. The sampling was usually performed daily during the spring flood, once in 1-3 days during rain floods, and once in 3-14 days during low flow periods.

To simulate different monitoring regularity, we manually decreased the temporal resolution of the actual data to various levels: once a week, once in 10 days, 2 weeks, a month, once in every hydrological season (winter low flow, rise, peak and fall of the spring flood, summer low flow, and major rain floods), and once in each calendar season.

Daily inputs for the reservoir model were created in two different ways: linearly interpolated from the resulting data sets, and calculated from the empirical relationships between water discharge and concentration (Sokolov et al., 2017; Yakimova and Solokov, 2018). 


\section{Results and Discussion}

One of the interesting findings of this study is the fact that the monitoring frequency has very limited impact on the estimates of the yearly mineral and organic matter yield (Sokolov, 2018; Yakimova and Sokolov, 2018). The mean calculation error increased only by $4-5 \%$ when the sampling frequency was reduced from 2 times a week to $1-2$ times a month, by $8-10 \%$ when upscaling to one observation per hydrological season, and, finally, reached $20 \%$ when only 4 observations per year were used.

As expected, seasonal patterns of the target parameters were more heavily affected by decreasing data resolution. Assessments made for individual seasons skewed up to $20 \%$ when only 1-2 measurements per month were provided, and with only one observation per hydrological season some individual errors reached 50-90\%. The maximum deviation was observed in the end of the winter low flow (before the rise of the spring flood) and during major rain floods. The errors appeared random and were strongly affected by the correlation between observation dates and key points of the hydrograph.

When using linear interpolation to recreate daily values of the chemical variables, increasing the original data set's time step from 2 times to 1 time a week did not significantly distance the modelled time series from actual observations, but thinning the input dataset to 2 observations per month caused the simulation quality to decrease by half, and to 1 observation per month - by approximately 4 times (according to MAE, RMSE and Nash-Sutcliffe efficiency values). The quality of empirical relationships between water discharge and chemical composition was also heavily dependent on the volume of input data set, and the best results were achieved when using separate equations for each of the hydrological seasons, which inherently dictates the need in finely detailed water quality monitoring.

\section{Conclusions}

The optimal water quality monitoring scheme on rivers should be determined based on the objective of a particular project. To assess the yearly chemical load of a river, it might be enough to obtain monthly or even once-a-season values of target parameters. Investigation of the seasonal dynamics of water quality requires observations at least twice a month. If there is an objective of gaining reliable empirical relationship between water discharge and water chemistry, it is necessary to provide maximum detail in observations during every significant hydrological event. It is strongly recommended to reference sampling dates with the key points in flow hydrograph regardless of any specific aim.

\section{Acknowledgments}

This study was supported by the Russian Geographical Society (project "The Moscow river from the headwaters to the mouth: hydrological and geochemical assessment of ecological state") with regard to methodology and data collection, and by RFBR with regard to river flow parametrization (project 19-05-50109) and model calculations (project 19-0500087 A).

\section{References}

Puklakov V.V., Datsenko Yu.S., Goncharov A.V. et al. 2015. Gidroekologicheskiy rezhim vodokhranilishch Podmoskov'ya (nablyudeniya, diagnoz, prognoz) [Hydroecological regime of the Moscow Region reservoirs (observation, diagnosis, prognosis)]. Moscow: Pero. (in Russian)

Puklakov V.V. 1999. Gidrologicheskaya model' vodokhranilishcha: rukovodstvo dlya pol'zovateley [Hydrological model of a reservoir: user guide]. Moscow: GEOS. (in Russian)

Sokolov D.I., Erina O.N., Tereshina M.A. 2017. Organic matter content in tributaries of Moskva River water supply system reservoirs: possibility of estimation in the absence of monitoring data. Inzhenernyye Izyskaniya [Engineering Survey] 8: 30-43. (in Russian)

Sokolov D.I. 2018. Assessment of organic matter flow in rivers: dependence on the details and interpretation methods of original data. In: Tret'i Vinogradovskie chteniya. Grani gidrologii [Third International Vinogradov Conference], pp. 461-466. (in Russian)

Yakimova A.I., Sokolov D.I., 2018. Ion flow assessment of the Mozhaysk Reservoir's tributaries depending on the details of original data. In: Tret'i Vinogradovskie chteniya. Grani gidrologii [Third International Vinogradov Conference], pp. 493-498. (in Russian) 